\title{
Identification of suitable reference genes for investigating gene expression in human gallbladder carcinoma using reverse transcription quantitative polymerase chain reaction
}

\author{
SHAN YU ${ }^{1}$, QIWEI YANG ${ }^{2}$, JING HUI YANG ${ }^{3}$, ZHENWU DU $^{2,4}$ and GUIZHEN ZHANG ${ }^{2,4}$ \\ ${ }^{1}$ Department of Neurology, China-Japan Union Hospital, Jilin University, Changchun, Jilin 130033; ${ }^{2}$ Central Laboratory, \\ Second Hospital, Jilin University, Changchun, Jilin 130041; ${ }^{3}$ Department of Hepatopancreatobiliary Surgery, \\ China-Japan Union Hospital, Jilin University, Changchun, Jilin 130033; ${ }^{4}$ Orthopedic Institute, \\ Second Hospital, Jilin University, Changchun, Jilin 130041, P.R. China
}

Received April 8, 2014; Accepted November 5, 2014

DOI: $10.3892 / \mathrm{mmr} .2014 .3008$

\begin{abstract}
Reverse transcription quantitative polymerase chain reaction (RT-qPCR) has become a frequently used strategy in gene expression studies. The relative quantification method is an important and commonly used method for the evaluation of RT-qPCR data. The key aim of this method is to identify an applicable internal reference gene, however, there are currently no suitable reference genes for gene analysis in gallbladder carcinoma. In the present study, screening was performed using 12 common reference genes, which were selected in order to provide an experimental basis for the investigation of gene expression in gallbladder carcinoma. A total of 16 tissue samples of gallbladder carcinoma and their matched normal gallbladder tissues were used. The gene expression stability and applicability of the 12 reference gene candidates were determined using the geNorm, NormFinder and BestKeeper software programs. Following comparison of the results of the three software programs, HPRT1 was identified as the most stably expressed reference gene. In the normal gallbladder group, the relative stably expressed reference gene was PPIA and in the entire sample group, the relatively stably expressed reference gene was PPIA. The present study also demonstrated that the combination of the three reference genes was the most appropriate. The recommended combinations were PPIA + PUM1 + ACTB for the total sample group, GAPDH + PBGD + ALAS1 for the gallbladder carcinoma group and PPIA + PUM1 + TBP for the paired normal gallbladder group.
\end{abstract}

Correspondence to: Ms. Guizhen Zhang or Professor Zhenwu Du, Central Laboratory, Second Hospital, Jilin University, 18 Ziqiang Street, Changchun, Jilin 130041, P.R. China

E-mail: zhangguizhenjlu@163.com

E-mail: doom99106@163.com

Key words: gallbladder carcinoma, reverse transcription quantitative polymerase chain reaction, reference gene, GeNorm, NormFinder, BestKeeper

\section{Introduction}

Reverse transcription quantitative polymerase chain reaction (RT-qPCR) is frequently used in gene expression studies and is currently considered the gold standard for accurate, sensitive and rapid measurements of gene expression(1). Relative quantification is an important and commonly used technique to evaluate RT-qPCR data, while the expression levels of target genes are compared to those of a stably expressed endogenous control gene, determined simultaneously in the same biological sample $(2,3)$. Therefore, the gene expression levels require normalization using reference genes in order to obtain reliable data. The identification of appropriate reference genes is a crucial stage involved in this approach. It is important for the ideal reference genes to be universally valid under the experimental conditions (1-3). In general, cellular maintenance genes are selected as reference genes to examine the variability between clinical samples. Several studies have demonstrated that the expression levels of these reference genes vary in different tissues or between treatments in the same tissue (4-5), as well as across cell types (6).

Gallbladder carcinoma is the most common type of malignant tumor of the biliary system worldwide; this type of tumor is highly fatal, with an overall 5-year survival rate of $<5 \%$ (7). In the majority of cases, this disease is rapid and silent, resulting in a poor prognosis, which has not improved over the last few decades. An effective therapeutic approach requires early diagnosis and timely surgery. Despite this potential for cure, $<10 \%$ of patients have tumors that are resectable at the time of surgery, whilst almost 50\% have lymph node metastasis (8). Gallbladder carcinoma has been regarded as one of the most difficult conditions to treat. Previous gene expression studies in gallbladder carcinoma tissue and normal gallbladder tissue counterparts have been performed to identify new predictive and prognostic molecular markers associated with gallbladder carcinoma (9-11). RT-qPCR is a frequently used technique to investigate these markers, thus, a review of the normalization standards used in the quantitative gene expression studies of gallbladder carcinoma was necessary. In the present study, the keywords gallbladder carcinoma or gallbladder cancer 
and RT-PCR were used in a PubMed search of previous studies. GAPDH is the most frequently used standard.(12,13), followed by ACTB $(14,15)$. The search results revealed that no systematic study has been performed on the selection of suitable reference genes for investigating target gene profiling in gallbladder carcinoma.

The present study aimed to identify the most suitable reference gene or set of genes for target gene profiling of gallbladder carcinoma. The stability of a panel of 12 common reference genes in gallbladder carcinoma tissues and paired normal gallbladder tissues from 16 patients were validated. The 12 candidate genes: ACTB, ALAS1, GAPDH, TBP, HPRT1, RPL29, PBGD, PPIA, PUM1, GUSB, B2M and 18S rRNA are frequently used as endogenous controls in the context of, but not restricted to, gallbladder carcinoma. A number of these genes have been identified as optimal reference genes in certain other cancer types, including HPRT1 and ACTB $(5,16)$. To investigate these genes, three common software packages, geNorm (17), NormFinder (18) and Bestkeeper (19) were used and to determine their validity, candidate reference genes were used to measure $\mathrm{C}$-myc levels, which are closely associated with gallbladder carcinoma (20). The aim was to provide useful information for the selection of suitable reference genes in further gene expression studies on gallbladder carcinoma tissues.

\section{Materials and methods}

Gallbladder carcinoma samples. A total of 16 gallbladder carcinoma samples were obtained between January 2008 and December 2013 with prior consent from untreated patients who underwent tumor resection surgery. Paired normal samples were collected from the adjacent non-tumor gallbladder tissues. All the specimens were obtained from patients at the China-Japan Union Hospital, Jilin University (Changchun, China) and snap-frozen in liquid nitrogen immediately following excision prior to storing at $-80^{\circ} \mathrm{C}$ until further processing. Only histologically confirmed tumor and non-neoplastic tissue samples were used for RNA analysis. Tumor stage was determined according to the International Union Against Cancer American Joint Committee on Cancer and International Union Against Cancer (21). The clinicopathological characteristics of the patients are summarized in Table I. The present study was approved by the Ethics Committee of the China-Japan Union Hospital.

RNA extraction and RT. A total of 50-100 mg tissue samples were homogenized in $1 \mathrm{ml}$ TRIzol reagent (Invitrogen Life Technologies, Carlsbad, CA, USA) and purified using an RNeasy Mini kit (Qiagen, Valencia, CA, USA). DNaseI was used to eliminate genomic DNA contamination. The concentrations and quality of the isolated RNA were measured using a Synergy HT enzyme standard instrument (BioTek, Winooski, VT, USA). The purity of total RNA was determined using the A260/A280 ratio. The standard of including RNA samples was 260/280 between 1.9 and 2.2. The integrity of the RNA samples was determined by electrophoresis on a $1 \%$ agarose gel (Invitrogen Life Technologies). The RT reaction was performed using an All.in.One ${ }^{\mathrm{TM}}$ First.Strand cDNA Synthesis kit (GeneCopoeia Inc., Rockville, MD, USA) in a total volume of $25 \mu \mathrm{l}$ according to the manufacturer's instructions.
Table I. Clinicopathological characteristic of patients.

\begin{tabular}{lc}
\hline $\begin{array}{l}\text { Clinicopathological } \\
\text { characteristic }\end{array}$ & $\begin{array}{c}\text { Patients with } \\
\text { gallbladder carcinoma }\end{array}$
\end{tabular}

Age (mean \pm standard deviation)

$50 \pm 16.7$

Gender

Male

10

Female

Histopathological type

Adenocarcinoma

16

Squamous cell carcinomas

0

TNM stage ${ }^{\mathrm{a}}$

$\begin{array}{ll}\mathrm{T}_{1 \mathrm{a}} \mathrm{N}_{0} \mathrm{M}_{0} & 3 \\ \mathrm{~T}_{1 \mathrm{~b}} \mathrm{~N}_{0} \mathrm{M}_{0} & 6 \\ \mathrm{~T}_{2 \mathrm{a}} \mathrm{N}_{1} \mathrm{M}_{0} & 3 \\ \mathrm{~T}_{2 \mathrm{~b}} \mathrm{~N}_{1} \mathrm{M}_{0} & 4\end{array}$

${ }^{a}$ According to the American Joint Committee on Cancer (21). TNM, tumor, node, metastasis.

RT- $q P C R$. The primers of 12 putative reference genes were designed using Primer Premier 5.0 software (Premier Biosoft, Palo Alto, CA , USA) and were synthesized by Sangon company (Beijing, China) as shown in Table II. A Roche LightCycler 480 detection system (Roche Diagnostics, GmbH, Mannheim, Germany) was used for RT-qPCR. Reactions were performed using All.in.One ${ }^{\mathrm{TM}}$ qPCR Mix (GeneCopoeia, Inc.) according to the manufacturer's instructions. All the samples were run in triplicate on 96-well plates. The PCR volume was $20 \mu \mathrm{l}$, containing $2 \mu \mathrm{l} \mathrm{cDNA}$. The following cycling conditions were used: $55^{\circ} \mathrm{C}$ for $5 \mathrm{~min} ; 95^{\circ} \mathrm{C}$ for $5 \mathrm{~min} ; 40$ cycles of $95^{\circ} \mathrm{C}$ for $20 \mathrm{sec}, 55^{\circ} \mathrm{C}$ for $20 \mathrm{sec}$ and $72^{\circ} \mathrm{C}$ for $4 \mathrm{~min}$. This cycle was followed by melting curve analysis, the baseline and cycle threshold values (Ct values) were automatically determined for all the plates using Roche LightCycler 480 software (Roche Diagnostics, Mannheim, Germany). A standard curve was constructed for each primer pair to determine the product specificity.

The $C_{t}$ values were identified by quantitative comparison of the amplification of the candidate genes. The $\mathrm{C}_{\mathrm{t}}$ values were calculated to relative quantities $(\mathrm{Q})$ for data analysis, in view of the PCR efficiencies of the candidate genes according to the equation: $\mathrm{Q}=2^{-\Delta C}$.

PCR efficiency. A random pool of cDNA from the samples was selected and used for 2-fold serial dilutions, ranging between $1 \mathrm{X}$ and 100,000X. The PCR were run in triplicate, as mentioned previously. The PCR efficiency was calculated using the slopes of the calibration curve and by the formula: $\mathrm{E}=10^{-1 / \text { slope }}$ (22). All PCR efficiencies are shown in Table II.

Statistical analysis. All the samples were divided into three groups: Gallbladder carcinoma, normal matching gallbladder and total sample groups. In order to better evaluate the stability of the reference genes, three frequently used software programs (geNorm, http://medgen.ugent.be/ jvdesomp/genorm/http:// 
Table II. Primer sequences, product size and polymerase chain reaction (PCR) efficiency.

\begin{tabular}{|c|c|c|c|}
\hline Gene & Primer sequence & Product size (bp) & PCR efficiency \\
\hline 18SrRNA & $\begin{array}{l}\text { F: CGGCTACCACATCCAAGGAA } \\
\text { R: GCTGGAATTACCGCGGCT }\end{array}$ & 186 & 2.11 \\
\hline GAPDH & $\begin{array}{l}\text { F: GACAGTCAGCCGCATCTTCT } \\
\text { R: TTAAAAGCAGCCCTGGTGAC }\end{array}$ & 127 & 1.99 \\
\hline $\mathrm{B} 2 \mathrm{M}$ & $\begin{array}{l}\text { F: AGCGTACTCCAAAGATTCAGGTT } \\
\text { R: ATGATGCTGCTTACATGTCTCGAT }\end{array}$ & 206 & 1.97 \\
\hline ACTB & $\begin{array}{l}\text { F: AGAAAATCTGGCACCACACC } \\
\text { R: TAGCACAGCCTGGATAGCAA }\end{array}$ & 173 & 1.97 \\
\hline ALAS1 & $\begin{array}{l}\text { F: GGCAGCACAGATGAATCAGA } \\
\text { R: CCTCCATCGGTTTTCACACT }\end{array}$ & 150 & 2.02 \\
\hline GUSB & $\begin{array}{l}\text { F: AGCCAGTTCCTCATCAATGG } \\
\text { R: GGTAGTGGCTGGTACGGAAA }\end{array}$ & 160 & 1.79 \\
\hline HPRT1 & $\begin{array}{l}\text { F: GACCAGTCAACAGGGGACAT } \\
\text { R: CCTGACCAAGGAAAGCAAAG }\end{array}$ & 132 & 1.96 \\
\hline PBGD & $\begin{array}{l}\text { F: AGTGTGGTGGGAACCAGC } \\
\text { R: CAGGATGATGGCACTGAACTC }\end{array}$ & 144 & 2.20 \\
\hline PPIA & $\begin{array}{l}\text { F: AGACAAGGTCCCAAAGAC } \\
\text { R: ACCACCCTGACACATAAA }\end{array}$ & 118 & 1.96 \\
\hline PUM1 & $\begin{array}{l}\text { F: CAGGCTGCCTACCAACTCAT } \\
\text { R: GTTCCCGAACCATCTCATTC }\end{array}$ & 211 & 2.01 \\
\hline RPL29 & $\begin{array}{l}\text { F: GGCGTTGTTGACCCTATTTC } \\
\text { R: GTGTGTGGTGTGGTTCTTGG }\end{array}$ & 120 & 2.00 \\
\hline TBP & $\begin{array}{l}\text { F: TGCACAGGAGCCAAGAGTGAA } \\
\text { R: CACATCACAGCTCCCCACCA }\end{array}$ & 132 & 2.16 \\
\hline C-myc & $\begin{array}{l}\text { F: GCCACGTCTCCACACATCAG } \\
\text { R: TGGTGCATTTTCGGTTGTTG }\end{array}$ & 132 & 1.98 \\
\hline
\end{tabular}

medgen.ugent.be/ jvdesomp/genorm/; NormFinder, http:// www.mdl.dk/publica-tionsnormfinder.htm; and BestKeeper, http://www.gene-quantification.de/bestkeeper.html) were selected. GeNorm is designed to establish reference genes for RT-qPCR and can be used to analyze and determine the M-value, which refers to the stability of the reference gene expression (17). The default value suggested by geNorm is $M=1.5$. The higher the $M$-value, the less stable and the lower the $\mathrm{M}$ value, the more stable. If $\mathrm{M}$ is $>1.5$, it is not suitable for use as a reliable reference gene. GeNorm software can also be used to analyze the pairwise variation value of the normalization factor $(\mathrm{V})$, which has a default value of 0.15 . The value of $\mathrm{V}_{\mathrm{n}} / \mathrm{V}_{\mathrm{n}+1}$ can be used to determine whether adding a new reference gene affects the normalization factor. If the value of $\mathrm{V}_{\mathrm{n}} / \mathrm{V}_{\mathrm{n}+1}$ is $>0.15$, it is necessary to use the $\mathrm{n}+1$ reference genes as internal controls. If it is $<0.15$, then it is not necessary to use new reference genes. NormFinder software is a tool designed to identify the optimal reference gene among a set of candidates and it has a similar operation principle to geNorm (4). This programme analyzes expression data, ranks the set of candidate normalization genes according to their expression stability and considers the gene with the minimum expression data as the most stable gene (19). This software can also be used to compare the stability of inter- and intra-group reference genes. BestKeeper evaluates candidate reference gene stability based on the standard deviation (SD) and correlation coefficient (r). An SD>1, is unsuitable for use as a stable and reliable reference gene. The remaining genes were ranked according to their $r$ value, the higher the $r$ value, the more the stable and reliable the gene.

Target gene relative expression analysis. The $\mathrm{C}-\mathrm{myc}$ proto-oncogene is involved in the process of malignant tumor formation (23). The present study measured C-myc as a target gene with the primer sequence shown in Table II. The relative expression levels of the target gene C-myc were calculated in the 16 paired samples according to the $2^{-\Delta \Delta C}$ method (24), with different candidate reference genes used as standards.

\section{Results}

RNA quality. To avoid erroneous results, only high-quality RNA samples were included in this study. The concentration, purity and integrity of the total RNA sample were determined. The mean A260/280 ratio of the RNA samples was $2.01 \pm 0.045(25)$ and the integrity of RNA samples was characterized by the $28 \mathrm{~S} / 18 \mathrm{~S}$ ratio $(>1.5)$ on $1 \%$ agarose gels. 


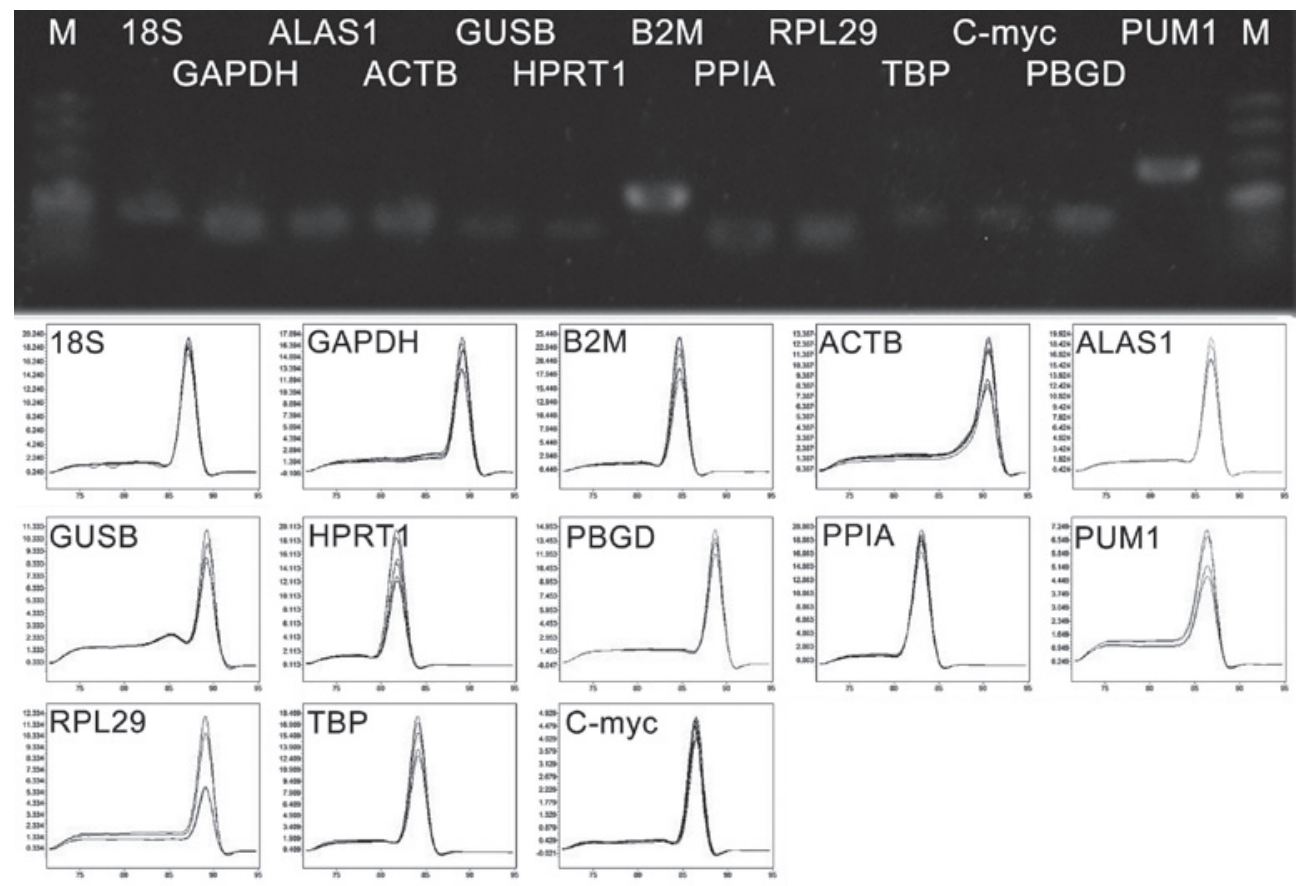

Figure 1. Specificity of qRT-PCR amplification: qRT-PCR amplification products were detected by $1 \%$ agarose gel electrophoresis and qRT-PCR amplification with melting curve analysis. RT-qPCR, reverse transcription quantitative polymerase chain reaction.

The primers sequences, corresponding length of the amplified products and PCR amplification efficiency is shown in Table I. There are two methods to verify the specificity of the primers, the RT-qPCR amplification products were detected by $1 \%$ agarose gel electrophoresis. The gel imaging system indicated that the size of the amplified fragment was consistent with the expected size, with a clear band and without primer dimers and nonspecific bands. In addition, the melting curve of each gene fragment amplified by qPCR revealed that all curves exhibited a single signal peak. For the candidate reference gene and target gene, the amplification efficiency range of the standard curve was 1.79-2.20 and all correlation coefficients were $>0.98$.

Gene expression levels. The expression level of the candidate reference genes was determined by the $\mathrm{Ct}$ value, which is inversely proportional to the expression level of the gene. Higher $\mathrm{Ct}$ values indicated smaller the expression quantities. As shown in Fig. 2, the $\mathrm{Ct}$ value of all the samples ranged between 14.92 and 37.64. In all groups, 18SrRNA had the smallest Ct values of $18.41 \pm 3.49,21.09 \pm 4.52$ and $15.72 \pm 0.85$ and PBGD had the greatest CT values of $32.88 \pm 4.19$, $35.29 \pm 3.73$ and $30.47 \pm 1.47$. There was a significant difference in the expression levels of the candidate reference genes between the gallbladder carcinoma tissues and its paired normal gallbladder tissues. Overall, the change in the $\mathrm{Ct}$ value of each group of candidate genes indicates that the expression level changed under different experimental conditions.

Stability analysis of the candidate reference gene. Theoretically, 12 reference genes constitute an appropriate internal for controlling genes. The measure used by the geNorm program uses to calculate the stability of gene expression is the M-value, among which the lowest M-value
$\mathbf{A}$

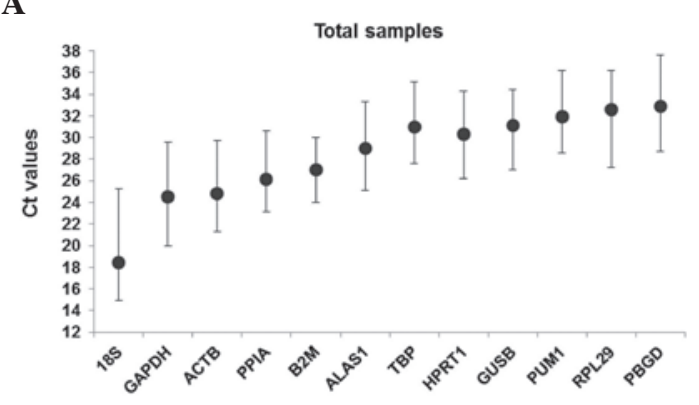

B
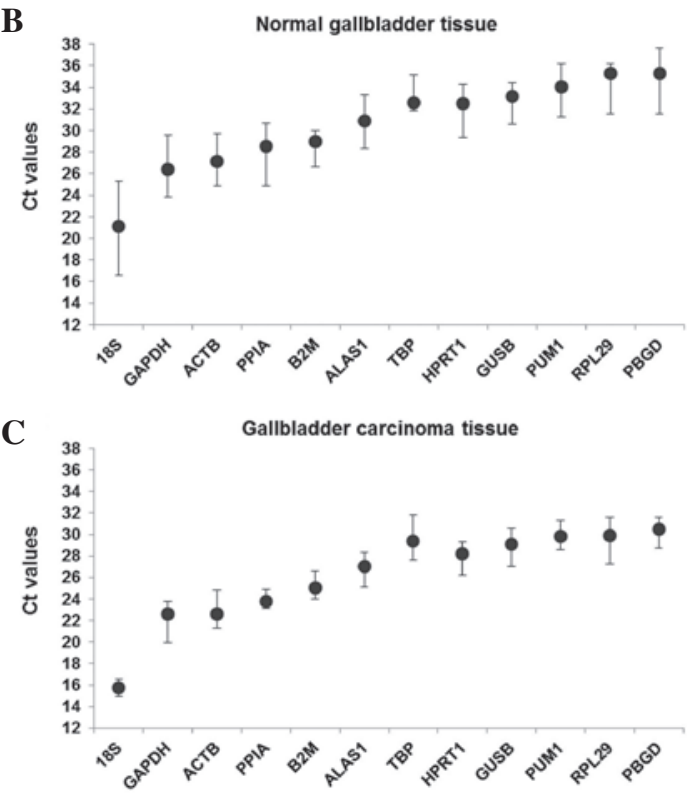

Figure 2. Mean $\mathrm{Ct}$ values of the reference genes in the experimental samples. Bars represent the mean \pm standard deviation; (A) Total sample group mean $\mathrm{Ct}$ values. (B) Normal gallbladder tissue group mean Ct values. (C) Gallbladder carcinoma tissue group mean $\mathrm{Ct}$ values. GAPDH, glyceraldehydes-3-phosphate dehydrogenase; ACTB, $\beta$-actin. 

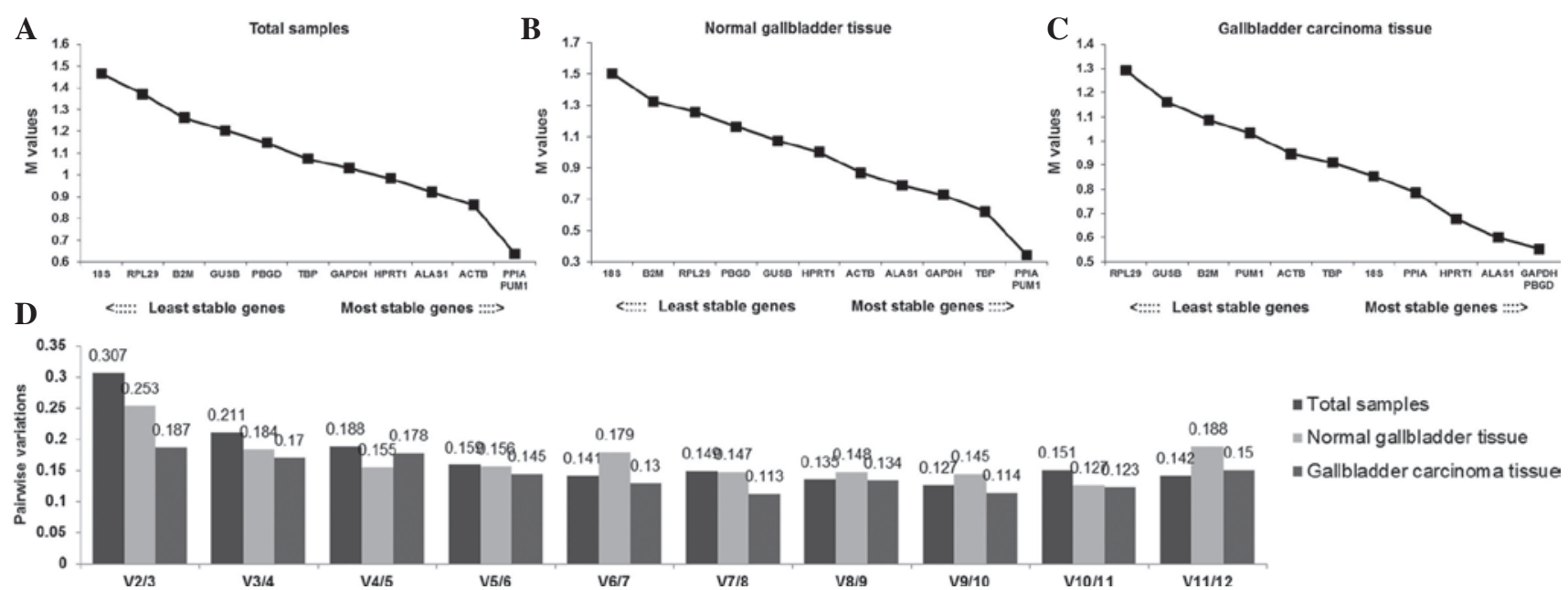

- Total samples

= Normal gallbladder tissue

- Gallbladder carcinoma tissue

Figure 3. GeNorm analysis of the candidate reference genes. Results are presented according to the output file of the geNorm program. (A, B and C) Stepwise exclusion of the least stable genes by calculating $\mathrm{M}$ value. The $\mathrm{x}$-axis from left to right indicates the ranking of the reference genes according to their expression stability and the y-axis indicates $\mathrm{M}$ (D) Determination of the optimal number of reference genes for normalization. M, the average expression stability; GAPDH, glyceraldehydes-3-phosphate dehydrogenase; ACTB, $\beta$-actin.

indicates the most stable expression. Based on ranking of M-values, the most unstable genes are gradually removed and the two most stable genes are determined simultaneously. The M-value of the 12 candidate reference genes in each group are shown in Fig. 3. In the total sample group and the normal gallbladder group, 18SrRNA had the biggest M value, suggesting that it is the most unstable candidate gene in the two groups. In these groups, PPIA and PUM1 $(\mathrm{M}=0.6)$ were determined to be the most stable genes. In the gallbladder carcinoma tissue group, GAPDH and PBGD were the most stable reference genes and RPL29 was the most unstable. The default threshold V-value is 0.15 , however, 0.15 is not an absolute cut-off value, but an ideal value, which is dependent on the expression of the genes and the diversity of the samples assessed (26). A combination of six reference genes in the total sample group was optimal (V6/7=0.141), while a combination of five genes was optimal in the gallbladder carcinoma group (V5/6=0.145). In the normal gallbladder group, a combination of seven reference genes was optimal $(\mathrm{V} 7 / 8=0.147)$.

In order to better evaluate the stability of the 12 reference genes, the present study also used the Normfinder program. As shown in Fig. 4 ALAS1 + PPIA was the most stable reference gene combination in the total sample group. HPRT1 was the most stably expressed gene in this group, followed by PPIA. The least stably expressed gene in the total sample group was 18SrRNA. In the gallbladder carcinoma group, HPRT1 was the most stably expressed gene, followed by PPIA. RPL29 was the least stably expressed gene in the gallbladder carcinoma group. In the paired normal gallbladder group, PPIA was the most stable reference gene, followed by PUM1, whilst 18SrRNA was the least stable gene (Fig. 4).

The BestKeeper program can also be used to compare the stability of internal reference genes. Since the BestKeeper program can only analyze 10 internal reference genes (19), the two most unstable internal reference genes indicated by the geNorm analyses were removed in each group. The BestKeeper analysis demonstrated that the $\mathrm{SD}$ values in the total sample group were all $>1$, however this was not consid-
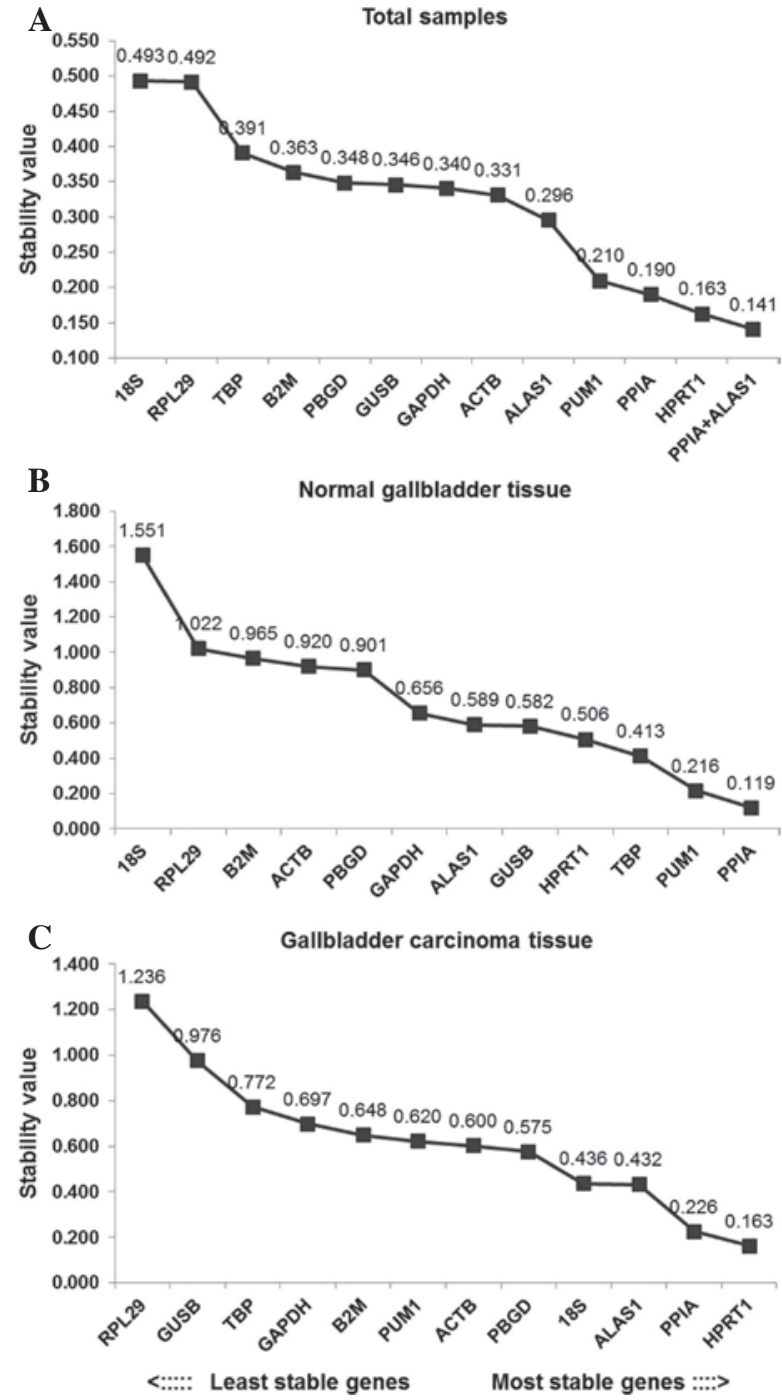

Figure 4. Candidate reference genes for normalization according to their expression stability calculated using the NormFinder program. The y-axis represents the stability value. The $\mathrm{x}$-axis from left to right represents the ranking of the reference genes. (A) Total sample group, (B) matching normal gallbladder group and (C) gallbladder carcinoma group. GAPDH, glyceraldehydes-3-phosphate dehydrogenase; ACTB, $\beta$-actin. 

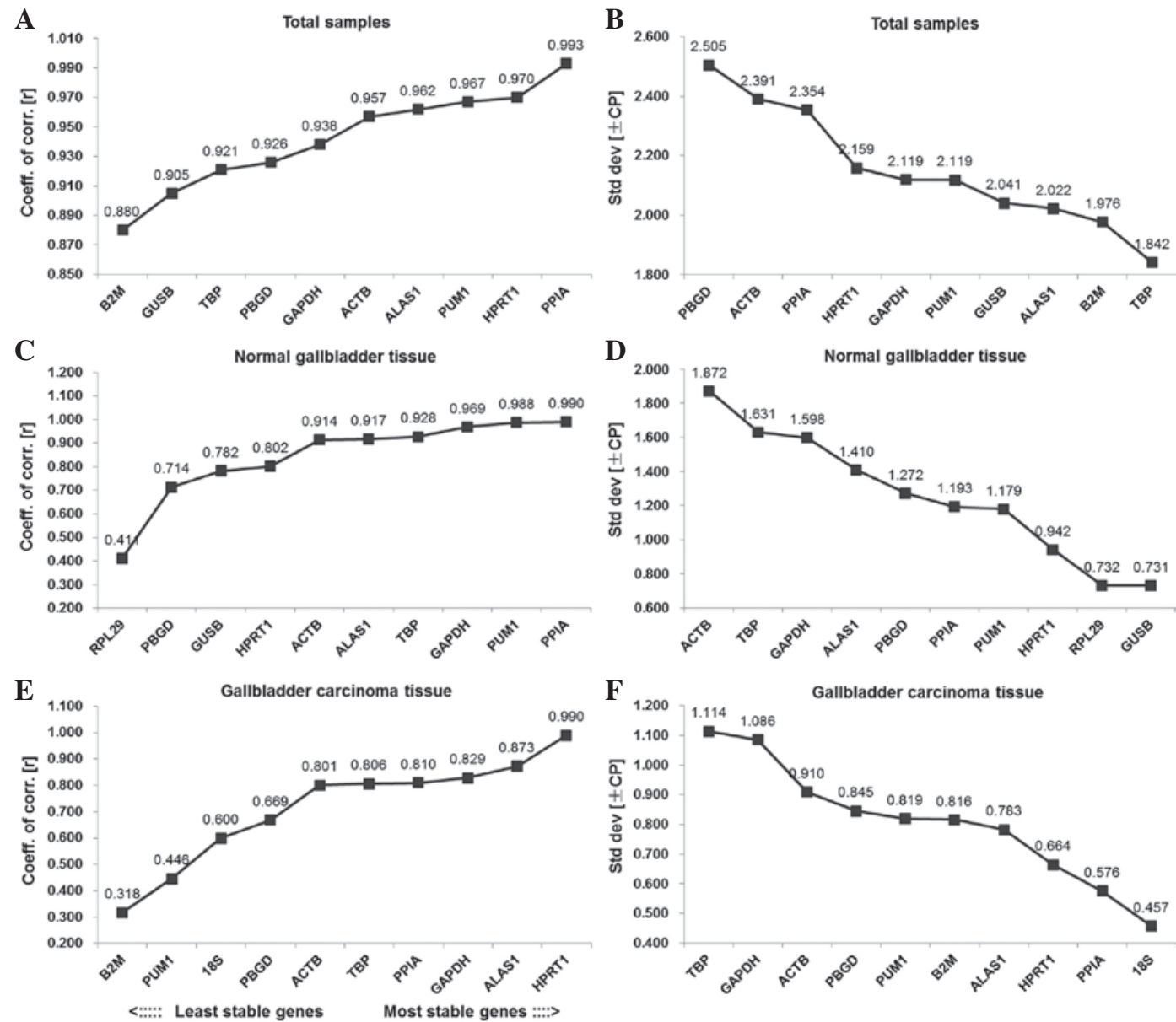

Figure 5. Stability values of the candidate reference genes evaluated using Bestkeeper softwear. The $\mathrm{r}$ values of the candidate reference genes and the standard deviation values of the candidate reference genes are presented in (A and B) for total samples, (C and D) for normal gallbladder tissues and (E and F) for gallbladder cacinoma tissues, respectively. The higher the $r$ value, the more stable the gene. Coeff. of corr, coefficient of correlation; Std dev, standard deviation; GAPDH, glyceraldehydes-3-phosphate dehydrogenase; ACTB, $\beta$-actin.

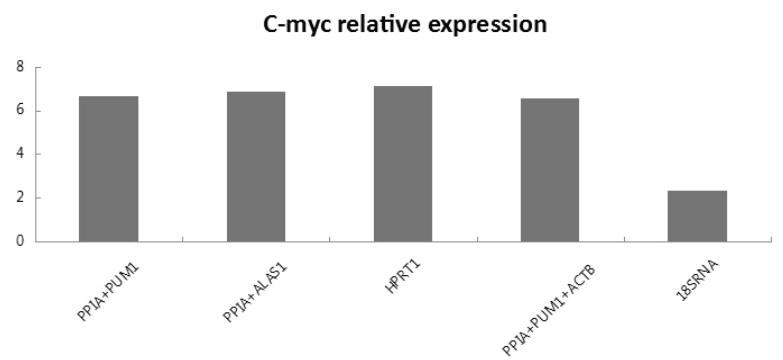

Figure 6. Relative quantification of the expression of C-myc, normalized by 18s DNA, HPRT1, ALAS1 + PPIA, PPIA + PUM1 and PPIA + PUM1 + ACTB in 16 pairs of samples. ACTB, $\beta$-actin.

ered to indicate that the 12 candidate internal reference genes were all unstable, since analysis using a single software program is not conclusive. In order of the SD value, the most stable internal reference gene in the total sample group was TBP. In the matching normal gallbladder group, the SD values of GUSB, RPL29 and HPRT1 were all <1. In terms of r-value, HPRT1 was the most stable internal reference gene. In the gallbladder carcinoma group, only the SD values of TBP and GAPDH were $>1$ and the r-values of the remaining candidate genes indicated that HPRT1 was the most stable internal reference gene.
Relative expression of $C-m y c$. The quantification of target gene expression was affected by selecting different reference genes. As shown in Fig. 6, when the recommended HPRT1 gene and the gene combinations ALAS1 + PPIA, PPIA + PUM1 and PPIA + PUM1 + ACTB, were set as references, no significant difference was observed in the gene expression of C-myc. However, when 18SrRNA was used as a reference gene for normalization, the relative expression of C-myc in malignant gallbladder tissue was markedly different, compared with using the previously mentioned reference gene as a standard. 


\section{Discussion}

In the detection of target gene expression, a gene with a steady expression level is required to normalize the data, these are internal reference genes $(2,3)$. Previous studies have indicated that the majority of these commonly used internal control genes have flaws. Their expression level varies significantly depending on various experimental conditions, including different cell types and tissues, different stages of cell proliferation and organ development and in vitro culture $(4,5,15)$. To the best of our knowledge, the present study is first to compare the stability of commonly used internal reference genes in gallbladder carcinoma tissue and their benign counterparts. As of studies investigating gallbladder carcinoma gene profiling develop, confirming stable and reliable internal control genes is required. In the present study, the reference genes commonly used in studies of gene expression in gallbladder carcinoma were used as were those frequently used in studies examining molecular markers in other cancer tissues.

To obtain accurate experimental data and reliable conclusions, the present study used an experimental process with a number of characteristics. Malignant and benign specimens from the same gallbladder were used to minimize differences between individuals. Due to limitations in the indications for gallbladder carcinoma surgery, biopsy specimens were not selected by grades and stages, as according to previous research, the expression of reference genes is not directly associated with the grades or stage of a malignant tumor $(5,27)$. The specimens were confirmed by the Pathology Department of the China-Japan Union Hospital as malignant and the gallbladder carcinoma samples used were the most common pathological types of adenocarcinoma. A total of 12 types of common reference genes were compared in terms of their expression stability and the geNorm, NormFinder and BestKeeper software programmes, commonly used to compare stability between reference genes, were selected for data analysis.

The geNorm program was used for initial analysis. This software program is based on a pairwise-comparison statistical model. By calculating the values of $\mathrm{M}$ and $\mathrm{V}$, the two most stable reference genes and the best reference gene combinations were determined. Following this analysis, the results suggested that in the total sample group and the paired normal gallbladder group, PPIA and PUM1 were the most stable reference genes. In the gallbladder carcinoma group, GAPDH and PBGD were the most stable reference genes. In addition, by calculating the value of $\mathrm{V}$, the optimal reference gene combinations of the total sample, gallbladder and paired normal gallbladder groups consisted of six, five and seven reference genes, respectively. The boundary value suggested by geNorm was 0.15 , however, rather than a stringent standard consideration, can provide guidance to determine the optimal number of reference genes. Regarding the standardized principle of RT-qPCR, previous studies recommend selecting at least three internal control genes to perform the relative quantitative investigation (16). The present study also recommended that a combination of three reference genes be most reliable. The recommended combinations for the total sample group were PPIA + PUM1 + ACTB, the gallbladder carcinoma group were GAPDH + PBGD + ALAS1 and the paired normal gallbladder group were PPIA + PUM1 + TBP. The results of the Normfinder software program, based on the analysis of variance as the statistical model, were the same. Finally, in order to reduce the one-sidedness of the computing models of the above-mentioned software programs, the Bestkeeper program was used for analysis. However, the results of BestKeeper differed to those from those of geNorm and Normfinder,. It has been suggested that the Bestkeeper statistical model differs from these and thus is less effective in ranking reference gene stability (28). Following comparison of the results from the three software programs, HPRT1 was the most stably expressed reference gene in the gallbladder carcinoma group. In the paired normal gallbladder group, the most stably expressed reference gene was PPIA and in total sample group, PPIA was the most stably expressed gene.

The gene expression of C-myc differed depending on the normalization method used, demonstrating the importance of reference genes to obtain reliable expression data. The C-myc gene is highly expressed in actively multiplying cells and several tumor cells. Previous studies have demonstrated that the expression of C-myc in gallbladder carcinoma tissues is higher than in gallbladder benign lesion tissues (29). The analysis of the relative expression level of C-myc in the present study also confirmed this. The present study used the most stable reference gene HPRT1 and the reference gene combinations ALAS1 + PPIA, PPIA + PUM1 and PPIA + PUM1 + ACTB, recommended by the geNorm and Normfinder software, and also used 18SrRNA, of relatively poor stability as the standard in relative quantification analysis. The result indicated that the relative expression levels of $\mathrm{C}$-myc were markedly different, suggesting the importance of a suitable reference gene for the gene profiling of gallbladder carcinoma. Similar erroneous normalizations have been performed in other tissues, including gastric cancer or in cell lines when inadequate control genes or normalizing strategies were performed $(15,30)$.

The present study identified the most suitable reference genes and reference gene combinations for gallbladder carcinoma tissue and paired normal gallbladder tissue for use in gene expression profile analysis. A reliable standardized method has the potential to improve understanding of the biological mechanisms underlying gallbladder carcinoma in the future. The relevant clarification of tumor molecular expression markers may improve the accuracy of diagnosis and estimation of prognostic factors and provide novel treatments.

\section{Acknowledgements}

This study was supported by the Key Foundation of Jilin Provincial Science and Technology Department (nos. 20130727038YY and 20100942) and the Jilin Provincial Development and Reform Commission (no. 20101928).

\section{References}

1. Radonić A, Thulke S, Mackay IM, Landt O, Siegert W and Nitsche A: Guideline to reference gene selection for quantitative real-time PCR. Biochem Biophys Res Commun 313: 856-862, 2004.

2. Bustin SA, Benes V, Nolan T and Pfaffl MW: Quantitative realtime RT-PCR - a perspective. J Mol Endocrinol 34: 597-601, 2005.

3. Derveaux S, Vandesompele $\mathbf{J}$ and Hellemans J: How to do successful gene expression analysis using real-time PCR. Methods 50: 227-230, 2010 
4. Andersen CL, Jensen JL and Ørntoft TF: Normalization of realtime quantitative reverse transcription-PCR data: a model based variance estimation approach to identify genes suited for normalization, applied to bladder and colon cancer data sets. Cancer Res 64: 5245-5250, 2004.

5. Ohl F, Jung M, Xu C, Stephan C, Rabien A, Burkhardt M, Nitsche A, Kristiansen G, Loening SA, Radonić A and Jung K: Gene expression studies in prostate cancer tissue: which reference gene should be selected for normalization? J Mol Med (Berl) 83 : 1014-1024, 2005.

6. Mansur NR, Meyer-Stegler K, Wurtz JC and Sirover MA: Cell cycle regulation of the glyceraldehydes-3-phosphate dehydrogenase/uracil glycosylase gene in normal human cell, Nucleic Acids Res 21: 993-998, 1993.

7. Lai CH and Lau WY: Gallbladder cancer - a comprehensive review. Surgeon 6: 101-110, 2008.

8. Siegel R, Naishadham D and Jemal A: Cancer statistics 2013. CA Cancer J Clin 63: 11-30, 2013.

9. Sheth S, Bedford A and Chopra S: Primary gallbladder cancer: recognition of risk factors and the role of prophylactic cholecystectomy. Am J Gastroenterol 95: 1402-1410, 2000.

10. Legan M: COX-2, P53, GLUT-1 as predictors of malignancy $n$ the development of gallbladder carcinomas. Bosn J Basic Med Sci 10: 192-196, 2010

11. Sun XN, Cao WG, Wang X et al: Prognostic impact of vascular endothelial growth factor-A expression in resected gallbladder carcinoma. Tumour Biol 32: 1183-1190, 2011.

12. Sergeant G, Lerut E, Ectors $\mathrm{N}$ et al: The prognostic relevance of tumor hypoxia markers in resected carcinoma of the gallbladder. Eur J Surg Oncol 37: 80-86, 2011.

13. Zhang JT, Sun W, Zhang WZ, Ge CY, Liu ZY, Zhao ZM, Lu XS and Fan YZ: Norcantharidin inhibits tumor growth and vasculogenic mimicry of human gallbladder carcinomas by suppression of the PI3-K/MMPs/Ln-5 $\gamma 2$ signaling pathway. BMC Cancer 14: 193, 2014.

14. Du X, Wu T, Lu J, Zang L, Song N, Yang T, Zhao H and Wang S: Decreased expression of chromodomain helicase DNA-binding protein 5 is an unfavorable prognostic marker in patients with primary gallbladder carcinoma. Clin TranslOncol 15: 198-204, 2013.

15. Huan P, Maosheng T, Zhiqian H, Long $\mathrm{C}$ and Xiaojun Y: TLR4 expression in normal gallbladder, chronic cholecystitis and gallbladder carcinoma. Hepatogastroenterology 59: 42-46, 2012.

16. Wisnieski F, Calcagno DQ, Leal MF, et al: Reference genes for quantitative RT-PCR data in gastric tissues and cell lines. World J Gastroenterol 19: 7121-7128, 2013.

17. Vandesompele J, De Preter K, Pattyn F, Poppe B, Van Roy N, De Paepe A and Speleman F: Accurate normalization of real-time quantitative RT-PCR data by geometric averaging of multiple internal control genes. Genome Biol 3: RESEARCH0034, 2002.
18. Kubista M, Andrade JM, Bengtsson M, Forootan A, Jonák J, Lind K, Sindelka R, Sjöback R, Sjögreen B, Strömbom L, Ståhlberg A and Zoric N: The realtime polymerase chain reaction. Mol Aspects Med 27: 95-125, 2006.

19. Pfaffl MW, Tichopad A, Prgomet C and Neuvians TP Determination of stable housekeeping genes, differentially regulated target genes and sample integrity: BestKeeper Excel-based tool using pair-wise correlations. Biotechnol Lett 26: 509-515, 2004.

20. Goldin RD and Roa JC: Gallbladder cancer: a morphological and molecular update. Histopathology 55: 218-229, 2009.

21. Edge S, Byrol BR, Compton CC, Fritz AG, Greene FL and Troti A (eds): American Joint Committee on Cancer. AJCC Cancer Staging Manual (M) 7th Edition, Springer, Chicago, IL, pp211-217, 2010.

22. Ginzinger DG: Gene quantification using real-time quantitative CR: an emerging technology hits the mainstream. Exp Hematol 30: 503-512, 2002

23. Brabletz T, Herrmann K, Jung A, et al: Expression of nuclear betacatenin and $\mathrm{c}-\mathrm{myc}$ is $\mathrm{c}$ orrelated with tumor size but not with proliferative activity of colorect aladenomas. Am J Pathol 156: 865-870, 2000.

24. Livak KJ and Schmittgen TD: Analysis of relative gene expression data using real-time quantitative PCR and the 2 (-Delta Delta C T)) Method. Methods 25: 402-408, 2001.

25 . Fleige $\mathrm{S}$, Walf $\mathrm{V}$, Huch $\mathrm{S}$ et al: Comparison of relative mRNA quantification models and the impact of RNA integrity in quantitative real-time RT-PCR, Biotechnol Lett 28: 1601-1613, 2006.

26. Wan H, Zhao Z, Qian C, et al: Selection of appropriate reference genes for gene expression studies by quantitative real-time polymerase chain reaction in cucumber. Anal Biochem 399: 257-261, 2010.

27. Li YL, Ye F, Hu Y, Lu WG and Xie X: Identification of suitable reference genes for gene expression studies of human serous ovarian cancer by real-time polymerase chain reaction. Anal Biochem 394: 110-116, 2009.

28. Kumar Vinod, Sharma R, Trivedi P, Vyas C, Govind K and Khandelwal V: Traditional and novel references towards systematic normalization of qRT-PCR data in plants. Crop Sci 511: e1455-e1468, 2011.

29. Cui Yong, Chen Yubing, Weng Gongyu, et al: Expression and significance of Survivin and C-myc in gallbladder carcinom, Chinese Journal of Coal Industry Medicine 10: 888-889, 2007 (In Chinese)

30. Liu S, Zhu P, Zhang L, et al: Selection of reference genes for RT-qPCR analysis in tumor tissues from male hepatocellular carcinoma patients with hepatitis B infection and cirrhosis. Cancer Biomark 13: 345-349, 2013. 